\title{
Letter:
}

\section{Phenolic contents and antioxidant capacities of Thai-Makham Pom (Phyllanthus emblica L.) aqueous extracts*}

\author{
Sitthichai IAMSAARD ${ }^{\dagger 1,2,3}$, Supatcharee ARUN ${ }^{1,2}$, \\ Jaturon BURAWAT ${ }^{1,2}$, Wannisa SUKHORUM ${ }^{1,2}$, \\ Jintanaporn WATTANATHORN ${ }^{3}$, \\ Somsak NUALKAEW ${ }^{4}$, Bungorn SRIPANIDKULCHAI ${ }^{2}$ \\ $\left({ }^{I}\right.$ Department of Anatomy, Faculty of Medicine, Khon Kaen University, \\ Khon Kaen 40002, Thailand) \\ $\left({ }^{2}\right.$ Center for Research and Development of Herbal Health Products, \\ Faculty of Pharmaceutical Sciences, Khon Kaen University, Khon \\ Kaen 40002, Thailand) \\ ( ${ }^{3}$ Integrative Complementary Alternative Medicine Research and \\ Development Group, Faculty of Medicine, Khon Kaen University, \\ Khon Kaen 40002, Thailand) \\ $\left({ }^{4}\right.$ Department of Pharmaceutical Sciences, Faculty of Pharmacy, \\ Mahasarakham University, Mahasarakham 44150, Thailand) \\ †E-mail: iamsaard_sitt@yahoo.com; sittia@kku.ac.th \\ Received Nov. 10, 2013; Revision accepted Feb. 10, 2014 \\ Crosschecked Mar. 10, 2014
}

doi: 10.1631 jzus.B1300284

Document code: A CLC number: Q505; R931.71

This study was aimed at determining the amount of the total phenolic contents (TPCs) and to evaluate the antioxidant activities of different extracts (leaves, branches, and barks) of Phyllanthus emblica (PE) L., a traditional medicinal plant that has been recently used as an anti-inflammatory, wound healing, and anti-aging agent. PE leaves, branches, or barks were aqueous-extracted and the amount of the TPC was determined using a Folin-Ciocalteu reagent method. The antioxidant activity of each PE extract was assessed using 1,1-diphenyl-2-picrylhydrazyl radical scavenging and ferric reducing antioxidant power (FRAP) methods. Among plant extracts, the PE bark extract possessed the highest TPC. The TPCs of the PE leaves, branches, and barks were (513.83 \pm 20.52$)$, $(650.50 \pm 9.76)$, and $(2196.33 \pm 11.02) \mathrm{mg}$ gallic acid equivalent/g dried material, respectively. Interest-

\footnotetext{
* Project supported by the Center for Research and Development of Herbal Health Products (RD-HHP), Faculty of Pharmaceutical Sciences, Khon Kaen University, Thailand (No. RD-HHP 05)

(C) Zhejiang University and Springer-Verlag Berlin Heidelberg 2014
}

ingly, the $\mathrm{IC}_{50}$, which was calculated from $50 \%$ inhibition against concentration $(\mu \mathrm{g} / \mathrm{ml})$ plot, of the PE leaf $((7.72 \pm 0.25) \mu \mathrm{g} / \mathrm{ml})$, branch $((6.92 \pm 0.22) \mu \mathrm{g} / \mathrm{ml})$, or bark $((6.54 \pm 0.27) \mu \mathrm{g} / \mathrm{ml})$ extract was lower than that of the ascorbic acid $((8.06 \pm 0.01) \mu \mathrm{g} / \mathrm{ml})$. As calibrated to the standard, the potent reducing power abilities of the PE leaf, branch, and bark extracts were (696.73 \pm 78.48$),(729.33 \pm 36.9)$, and $(966 \pm 64.73) \mathrm{mg} / \mathrm{g}$ ascorbic acid equivalent, respectively.

The Phyllanthus emblica L. (also called "Makham Pom" in Thai) is a traditional medicinal plant that has been used in many Asian countries including Thailand. Focusing on the fruit, it has been demonstrated that the fruits of PE are rich in phenolics (She et al., 2013) and possess antioxidant activities (Chalise et al., 2010; Sawant et al., 2010). In addition, PE fruits have been proven to have many therapeutic properties (Krishnaveni and Mirunalini, 2010; Chularojmontri et al., 2013). PE fruits have been used for anti-inflammation, anti-aging, and anti-melanogenesis. Besides the fruits, in Thailand, the leaves, branches, and barks of PE have also been used for many traditional treatments. PE leaves and branches (by boiling them in a cup of water) are used for reducing fever and edema. Moreover, the fresh extracts of PE leaves and branches are used for anti-inflammatory and external wound healing treatments. For additional uses of the PE barks, they have been used as a stringent, astringent drug, for wound healing in the oral cavity, and in treating of dermatitis. Recently, it has been demonstrated as a potential nanoemulsion product, developed from PE branch extract, which has a high entrapment efficiency (Chaiittianan and Sripanidkulchai, 2013). Because the developed-PE nanoemulsion particle is small, stable, and can release phytochemical components, it is also promising to apply it for skin treatments. These applications may include such applications as cosmetic cream, muscle pain relief balm, and herbal-compress ball. With its 
various medicinal properties, the PE trees are commonly planted in the agriculture farms as an economic plant in many provinces in Thailand. Although many parts of the PE trees have been believed to possess various medicinal activities, the scientific demonstration of the amount of the TPCs and antioxidant activities of particular PE leaf, branch, and bark aqueous extracts is still limited. To gain basic medicinal data of PE before treating in research animals or humans for future clinical trials, this study attempted to primarily demonstrate the total phenolics and in vitro antioxidant activities of different part aqueous extracts of Thai $P$. emblica.

In our study, the results showed that three different parts of the PE extracts possessed the total phenolics (Fig. 1) as determined from the calibration curves of the gallic acid $\left(Y=5.4081 x+0.093, R^{2}=\right.$ 0.9968 , where $Y$ is peal area, $x$ is the concentration $(\mu \mathrm{g} / \mathrm{ml})$ of the marker compound). In comparison, however, it was significantly demonstrated that the bark extract contained the highest TPC ((2196.33 11.02) $\mathrm{mg}$ gallic acid equivalent/g dried material), followed by the branch and leaf extracts $((650.50 \pm$ 9.76) and (513.83 \pm 20.52$) \mathrm{mg}$ gallic acid equivalent/g dried material, respectively).

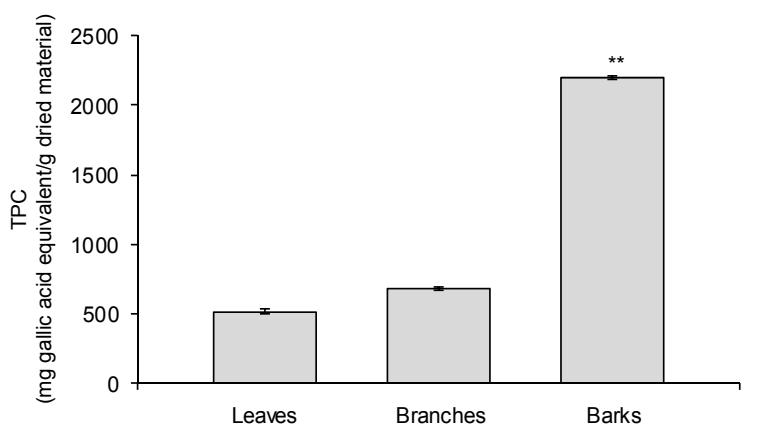

Fig. 1 Amount of total phenolic contents (TPCs) of the leaf, branch, and bark aqueous extracts of $P$. emblica (PE) using the Folin-Ciocalteu reagent method Data are expressed as mean $\pm \mathrm{SD}(n=3)$. ${ }^{* *} P<0.01$ vs. leaves or branches

For the 2-diphenyl-picrylhydrazyl (DPPH) scavenging assay, the results showed that each part of the PE extracts possessed a concentration-response relationship in the DPPH scavenging activity which was similar to the trend of positive control (ascorbic acid). As compared to $\mathrm{IC}_{50}$ of ascorbic acid $((8.06 \pm 0.01) \mu \mathrm{g} / \mathrm{ml})$, the $\mathrm{IC}_{50}$ of PE leaf $((7.72 \pm 0.25) \mu \mathrm{g} / \mathrm{ml})$, branch $((6.92 \pm$ $0.22) \mu \mathrm{g} / \mathrm{ml})$, or bark $((6.54 \pm 0.27) \mu \mathrm{g} / \mathrm{ml})$ extract was very close to and lower than that of the ascorbic acid (Table 1).
Table 1 Antioxidant activities of the leaf, branch, and bark aqueous extracts of $P$. emblica (PE) by using the DPPH radical method

\begin{tabular}{lc}
\hline Standard/PE extract & $\mathrm{IC}_{50}(\mu \mathrm{g} / \mathrm{ml})$ \\
\hline Ascorbic acid (standard) & $8.06 \pm 0.01$ \\
Leaves & $7.72 \pm 0.25$ \\
Branches & $6.92 \pm 0.22$ \\
Barks & $6.54 \pm 0.27$ \\
\hline
\end{tabular}

Data are expressed as mean $\pm \mathrm{SD}(n=3)$

In the reducing power capacity assay, the results showed that each part extract of the PE displayed concentration-dependent increases in the reducing power as also shown in the calibrated standard ascorbic acid ( $\left.Y=0.007 x+0.3769, R^{2}=0.9802\right)$. Among the PE extracts, the result (Fig. 2) showed that the PE bark extract had the highest reduction levels of ferric ion to ferrous sulfate $((966 \pm 64.73) \mathrm{mg} / \mathrm{g}$ ascorbic acid equivalent) as compared to the PE branch and leaf extracts $((729.33 \pm 36.9)$ and $(696.73 \pm 78.48) \mathrm{mg} / \mathrm{g}$ ascorbic acid equivalent, respectively).

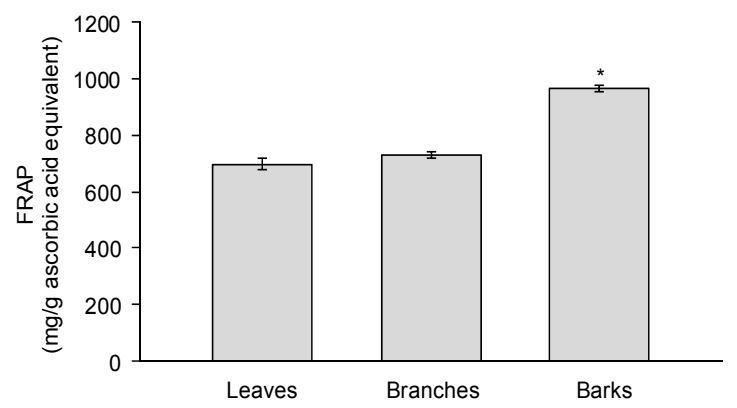

Fig. 2 Ferric reducing antioxidant powers (FRAPs) of the leaf, branch, and bark aqueous extracts of $P$. emblica (PE)

Data are expressed as mean $\pm \mathrm{SD}(n=3) .{ }^{*} P<0.05$ vs. leaves or branches

The PE fruit aqueous extract should be also assayed in parallel to compare those phenolics and antioxidant activities of its leaf, branch, and bark extracts. Unfortunately, the season for PE fruit production in July was limited, but it is assumed to have those capacities as previously demonstrated (Krishnaveni and Mirunalini, 2012; She et al., 2013). In traditional use, however, both fresh and dried samples of PE leaves, branches, or barks have been used in all seasons. According to recent results, it implies that besides PE fruits (produced once a year), the rest of the parts of the PE tree can be used at least in July for traditional uses or for experimental research. In Thai 
traditional medicine, PE barks have been used as a stringent, astringent drug, for wound healing in the oral cavity, and also in the treating of dermatitis. These properties of PE may be partially explained and supported by the traditional uses since the PE branch extract showed amounts of total phenolic compounds and antioxidant activities. To our knowledge, PE bark aqueous extract here is demonstrated to possess the highest amount of total phenolics and antioxidant activities as compared to the rest of the parts. In the review of literature, $\alpha$-tocopherol, ascorbic acid, and reduced glutathione are three major molecules commonly present in all higher plants and have antioxidant capacity (Shao et al., 2008). Since PE is classified as a higher plant, it may also contain such antioxidant molecules, especially rich in the bark sample. However, the profile of those molecules in PE parts needs to be further investigated. If the antioxidant molecule amount of PE bark has demonstrated to be higher than those of the other parts, it can be used as a good part for clinical trials in herbal drug developments and other medical applications.

\section{Materials and methods}

\section{Chemicals and reagents}

Folin-Ciocalteu reagent, DPPH, acetate buffer, 2,4,6-tripyridyl-s-triazine (TPTZ), and ferric chloride $\left(\mathrm{FeCl}_{3}\right)$ were purchased from Sigma-Aldrich Co., Ltd. Thailand. Ascorbic acid, gallic acid, and other chemicals were of analytical grade.

\section{Plant collection and extraction}

All parts (leaves, branches, and barks) of the PE were collected from the Khundong 58 Punmai Farm, Muang, Khon Kaen, Thailand, in July 2013. The plant samples were further authenticated for their actual species by Prof. Dr. Pranom CHANTARANOTHAI, a plant taxonomist, Department of Biology, Faculty of Science, Khon Kaen University (KKU), Thailand. The voucher specimens of PE were deposited in the KKU Herbarium (\#Supatcharee Arun 01 [KKU]). For extraction, the fresh leaves, branches, or barks of the PE were washed with distilled water and dried in a hot oven $\left(60{ }^{\circ} \mathrm{C}\right)$ for $5 \mathrm{~d}$, since PE has been commonly prepared and used in the dried material form. Each dried sample was crushed by a Hammer mill crusher (AEG IP54 Lbi 07, Germany) for $30 \mathrm{~min}$. Then, $2 \mathrm{~kg}$ of each crushed sample was extracted with $10 \mathrm{~L}$ of distilled water at $95-100{ }^{\circ} \mathrm{C}$ for $30 \mathrm{~min}$ and filtered using nylon clothes. Sequentially, each filtrate was dried using a spray dryer (Nitro A/S-Gladsaxeveg 305-DK-2860, Soeborg, Denmark) (Toyang et al., 2012), as calculated from a formula of yield $(\%)=$ (weight of plant powder extract after extraction) $/(2 \mathrm{~kg}$ of dried plant before extraction $) \times 100 \%$, and the extraction yields of leaves, branches, and barks of the PE aqueous extracts were 9.94\%, 7.07\%, and 12.68\%, respectively. Each sample was further prepared as concentrated extract stock of $2 \mathrm{mg} / \mathrm{ml}$ (dissolved with distilled water) before assessment.

\section{Determination of TPC}

The amount of TPC in PE extract (leaves, branches, or barks) was measured using the Folin-Ciocalteu reagent method as previously described (Singleton et al., 1999). Briefly, each aqueous PE extract (0.2 ml, $0.01 \mathrm{mg} / \mathrm{ml}$ ) was added into a test tube containing $1 \mathrm{ml}$ of the Folin-Ciocalteu reagent $(10 \%, \mathrm{v} / \mathrm{v})$ and incubated for $5 \mathrm{~min}$ before adding $3 \mathrm{ml}$ of $0.2 \mathrm{~g} / \mathrm{ml}$ sodium carbonate. After mixing the solution thoroughly, the mixed sample was further incubated at room temperature in a dark room for $2 \mathrm{~h}$ with intermittent shaking. The absorbance was measured at $765 \mathrm{~nm}$ using an ultraviolet-visible spectrophotometer (Jasco V530, Japan). All samples were tested in triplicate. The standard sample used to gain a calibration curve was at five concentrations of diluted gallic acid solutions $(0.026,0.040,0.064,0.080$, and $0.160 \mathrm{mg} / \mathrm{ml}$ ). The results of the TPCs were expressed as gallic acid equivalents in milligram per gram of dry sample.

\section{DPPH radical scavenging assay and determina- tion of $\mathrm{IC}_{\mathbf{5 0}}$}

The radical scavenging activity of each part of the PE extracts was determined by using a DPPH assay as previously described (Brand-Williams et al., 1995). Briefly, the distilled water-diluted solution of the PE leaf, branch, or bark extract was prepared from a concentrated extract stock into five concentrations $(1.60,4.27,6.10,9.60$, and $12.80 \mu \mathrm{g} / \mathrm{ml})$ to perform a concentration plot. Then, each concentration of extract $(2 \mathrm{ml})$ was mixed with $2 \mathrm{ml} \mathrm{DPPH}$ in methanol $(0.004 \%)$ during $30 \mathrm{~min}$ at room temperature in a dark room. The absorbance was recorded at $517 \mathrm{~nm}$ using an ultraviolet-visible spectrophotometer. The ascorbic acid $(1,3,5,8$, and $14 \mu \mathrm{g} / \mathrm{ml})$ was used as the positive standard. All samples and the standard were 
measured in triplicate. The scavenging activity of the extracts or standard was calculated as the percent inhibition of DPPH radical scavenged activity using the formula of (absorbance of control-absorbance of sample $) /($ absorbance of control $) \times 100 \%$. Data were expressed as the $\mathrm{IC}_{50}$.

\section{FRAP assay}

Reducing power capacity was determined using an FRAP assay as previously described (Benzie and Strain, 1996). Briefly, $0.1 \mathrm{ml}$ of each PE sample (prepared from a stock solution) at six different concentrations $(0.80,2.00,5.12,9.00,12.80$, and $32.00 \mu \mathrm{g} / \mathrm{ml}$ ) was mixed with $3 \mathrm{ml}$ of FREP reagent (300 $\mathrm{mmol} / \mathrm{L}$ acetate buffer, $10 \mathrm{mmol} / \mathrm{L}$ TPTZ, $\left.20 \mathrm{mmol} / \mathrm{L} \mathrm{FeCl}_{3}(10: 1: 1, \mathrm{v} / \mathrm{v} / \mathrm{v})\right)$. The mixture was incubated in a dark room for $20 \mathrm{~min}$ and the absorbance was recorded at $593 \mathrm{~nm}$ using an ultravioletvisible spectrophotometer. For standard preparation, six concentrations of ascorbic acid $(5.76,9.60,17.28$, $24.00,32.00$, and $48.00 \mu \mathrm{g} / \mathrm{ml}$ ) were plotted to determine the reducing power.

\section{Compliance with ethics guidelines}

Sitthichai IAMSAARD, Supatcharee ARUN, Jaturon BURAWAT, Wannisa SUKHORUM, Jintanaporn WATTANATHORN, Somsak NUALKAEW, and Bungorn SRIPANIDKULCHAI declare that they have no conflict of interest.

This article does not contain any studies with human or animal subjects performed by any of the authors.

\section{References}

Benzie, I.F.F., Strain, J.J., 1996. The ferric reducing ability of plasma (FRAP) as a measure of "antioxidant power": the FRAP assay. Anal. Biochem., 239(1):70-76. [doi:10. 1006/abio.1996.0292]

Brand-Williams, W., Cuvelier, M.E., Berset, C., 1995. Use of a free-radical method to evaluate antioxidant activity.
Lebensm.-Wiss. Technol., 28(1):25-30. [doi:10.1016/ S0023-6438(95)80008-5]

Chaiittianan, R., Sripanidkulchai, B., 2013. Development of a nanoemulsion of Phyllanthus emblica L. branch extract. Drug Dev. Ind. Pharm., online. [doi:10.3109/03639045. 2013.838580]

Chalise, J.P., Acharya, K., Gurung, N., et al., 2010. Antioxidant activity and polyphenol content in edible wild fruits from Nepal. Int. J. Food Sci. Nutr., 61(4):425-432. [doi: 10.3109/09637481003591590]

Chularojmontri, L., Suwatronnakorn, M., Wattanapitayakul, S.K., 2013. Phyllanthus emblica L. enhances human umbilical vein endothelial wound healing and sprouting. Evid. Based Complement. Alternat. Med., 2013:720728. [doi:10.1155/2013/720728]

Krishnaveni, M., Mirunalini, S., 2010. Therapeutic potential of Phyllanthus emblica (amla): the ayurvedic wonder. J. Basic Clin. Physiol. Pharmacol., 21(1):93-105.

Krishnaveni, M., Mirunalini, S., 2012. Chemopreventive efficacy of Phyllanthus emblica L. (amla) fruit extract on 7,12-dimethylbenz(a)anthracene induced oral carcinogenesis - a dose-response study. Environ. Toxicol. Pharmacol., 34(3):801-810. [doi:10.1016/j.etap.2012.09.006]

Sawant, L., Pandita, N., Prabhakar, B., 2010. Determination of gallic acid in Phyllanthus emblica Linn. dried fruit powder by HPTLC. J. Pharm. Bioallied Sci., 2(2):105-108. [doi:10.4103/0975-7406.67012]

Shao, H.B., Chu, L.Y., Lu, Z.H., et al., 2008. Primary antioxidant free radical scavenging and redox signaling pathways in higher plant cells. Int. J. Biol. Sci., 4(1):8-14. [doi:10.7150/ijbs.4.8]

She, G., Cheng, R., Sha, L., et al., 2013. A novel phenolic compound from Phyllanthus emblica. Nat. Prod. Commun., 8(4):461-462.

Singleton, V.L., Orthofer, R., Lamuela-Raventos, R.M., 1999. Analysis of total phenols and other oxidation substrates and antioxidants by means of Folin-Ciocalteu reagent. In: Packer, L. (Ed.), Methods in Enzymology. Academic Press Inc., San Diego, Vol. 299, p.152-178.

Toyang, N.J., Ateh, E.N., Keiser, J., et al., 2012. Toxicity, antimicrobial and anthelmintic activities of Vernonia guineensis Benth. (Asteraceae) crude extracts. J. Ethnopharmacol., 144(3):700-704. [doi:10.1016/j.jep.2012. 10.016]

\section{中文㩯要:}

本文题目: 泰国余甘子水提物中总酚含量及抗氧化活性

Phenolic contents and antioxidant capacities of Thai-Makham Pom (Phyllanthus emblica L.) aqueous extracts

本文概要: 通过对余甘子不同部位（叶、枝和树皮）水提物的总酚含量的测定及体外抗氧化活性的研究, 为其体内及临床试验研究奠定了基础。余甘子叶、枝和树皮的水提物皆具有抗氧化活性，其中 树皮中的总酚含量最高, 抗氧化活性最强。

关键词组：余甘子; 总酚含量; 抗氧化能力；传统药用植物 